\title{
ASSOCIATED FACTORS OF TREATMENT COMPLIANCE AMONG HYPERTENSIVE PATIENTS OF SELECTED HOSPITAL OF RUPENDEHI
}

Ikshaya Rana, ${ }^{1}$ Pragya Shrestha, ${ }^{1}$ Astha Sharma Pokharel

\begin{abstract}
INTRODUCTION

Hypertension is a chronic medical health problem which needs adequate treatment management. It is important to understand the factors affecting compliance in patients to achieve successful treatment compliance. Here study aim to identify the associated factors of medication adherence among hypertensive patients.
\end{abstract}

\section{MATERIAL AND METHODS}

We conducted a hospital-based cross-sectional study in UCMS Bhairahawa from April to November 2019. We collected data of 384 hypertensive patients who are in medication of hypertension for at least 6 months. Data was collected by interview method and the medication adherence was measured by eight questions that were developed following the Morisky-Green Test and analyzed by using descriptive and inferential statistics with SPSS software version 22.

\section{RESULTS}

Good adherence with medication was observed in $58 \%$ of the 384 hypertensive patients. Female patients (56.2\%) were found to be more likely to adhere to their medication regime, compare to their male patients (43.8\%). Multinomial logistic regression indicates that patients who have own house were 6.6 times likely (95\% CI: 2.28-19.29 P<0.00) to adhere; compare to live in rent house. It is also appeared that the patients on medication 6 to 10 years were 0.14 more likely to be compliant compared to the hypertensive patients who were on medication more than 10 years (95\% CI: .022-0.94; $\mathrm{P}<0.043$ ). Availability of the antihypertensive drugs near the house (more than 5 minutes of walking) is important to reduce the poor adherence $(\mathrm{OR}=12.2, \mathrm{CI}: 1.1-104.1 ; \mathrm{P}<.022)$.

\section{CONCLUSION}

Adherence level were higher in female patients who are live in own house having medication for 6 to 10 years. Availability of the hypertensive drugs near to house (more than 5 minutes of walking) is also important to reduce the non-adherence on hypertensive drugs.

KEYWORDS Compliance=adherence, Hypertension, Cross-sectional study

1. Universal College of Nursing Sciences, UCMS, Bhairahawa, Nepal

DOI: http//doi.org/10.3126/jucms.v8i1.29788

\author{
For Correspondence \\ Ms. Ikshaya Rana \\ Universal College of Nursing Sciences \\ UCMS, Bhairahawa, Nepal \\ Email: ikshayarana@gmail.com
}




\section{INTRODUCTION}

High blood pressure is a significant public health problem in many low or middle income countries. Hypertension is a major risk factor for heart diseases, stroke, myocardial infarction, renal failure and blindness. In worldwide 9.4 million deaths and $7 \%$ of diseases burden due to the HTN. An estimated word population above age 18 years adults $22 \%$ was affected by HTN. ${ }^{1}$ Hypertension is defined as having a blood pressure higher than 140 over $90 \mathrm{~mm} \mathrm{Hg}$, with a consensus across medical guidelines. ${ }^{2}$ Patients' noncompliance with treatment is a predominant reason for failing to control hypertension. ${ }^{3}$ WHO defines adherence as "the extent to which a person's behavior-taking medication, following a diet, and/or executing lifestyle changes corresponds with agreed recommendations from a health-care provider". ${ }^{4}$ In Ethiopian study, $23 \%$ of the hypertensive patients were compliant to the lifestyle manifestations advised by their physicians. 5 Medication regimen are essential to slow down disease progression and delay the onset of complications ${ }^{6}$ In the case, multiple drug therapy and multiple frequency of dosing also increase the risk of non-compliance ${ }^{7}$ and low adherence was also found $41 \%$ in Bangladesh, 53.4\% in Malaysia and 51.9\% in Nepal among hypertensive patients. ${ }^{8-10}$ We have not found sufficient study conducted in Nepal to identify the associated factors of treatment adherence with anti hypertensive patients.

Many studies were conducted in different low- middle income countries, have demonstrated unsuccessfully treated for reasons such as poor or low adherence. ${ }^{11}$ So that it is important to identify the associate factors with the low adherence in hypertensive medication. This study will help to take necessary action to the management of hypertension with the method of the medication. High blood pressure is now growing as a major public health challenge around the globe. Poor compliance to anti-hypertensive therapy is one of the biggest obstacles in therapeutic control of high blood pressure. Nepal being a developing country, high blood pressure has been identified as the leading risk factor for mortality and is major cause of disease burden due to a change in life style and sedentary life. Several studies have shown that, hypertensive patients don't take their medications as prescribed.

Thus this data provided by study aimed to assess factor for treatment adherence among HTN patients. This study was done to identify the associated factors of treatment compliance among hypertensive patients in Rupendehi district and to determine the association between demographic factors and treatment compliance among hypertensive patients

\section{MATERIAL AND METHODS}

We conducted a hospital-based cross-sectional study in
UCMS Bhairahawa from April to November 2019. We collected data of 384 hypertensive patients who are in medication of hypertension for at least six months. Data was collected by interview method and Patients were selected by convenience sampling and written informed consent was obtained. The study was approved by institutional review of committee (IRC), UCMS.

The medication adherence was measured by eight questions that were developed following the Morisky-Green Test ${ }^{12,13}$ and analyzed by using descriptive and inferential statistics with SPSS software version 22. Multi-logistic regression analysis was conducted to get the odds ratios of factors with medication adherence.

\section{RESULTS}

Table 1. Socio-demographic characteristics of respondents

\begin{tabular}{|c|c|c|}
\hline Variable & Frequency & Percentage \\
\hline $\begin{array}{l}\text { Gender } \\
\text { Male } \\
\text { Female } \\
\text { Age(years) }\end{array}$ & $\begin{array}{l}168 \\
216\end{array}$ & $\begin{array}{l}43.8 \\
56.2\end{array}$ \\
\hline $30-39$ & 17 & 4.4 \\
\hline $40-49$ & 85 & 22.1 \\
\hline $50-59$ & 109 & 28.4 \\
\hline $\begin{array}{l}\geq 60 \\
\text { Mean age } \pm \text { SD } \\
57.04 \pm 10.03 \\
\text { Residence }\end{array}$ & 173 & 45.1 \\
\hline Urban & 355 & 92.4 \\
\hline rural & 29 & 7.6 \\
\hline $\begin{array}{l}\text { Marital Status } \\
\text { Married } \\
\text { Unmarried } \\
\text { Widowed } \\
\text { Type of House }\end{array}$ & $\begin{array}{l}364 \\
18 \\
2\end{array}$ & $\begin{array}{r}94.8 \\
4.5 \\
.5\end{array}$ \\
\hline Own & 306 & 79.7 \\
\hline Rented & 78 & 20.3 \\
\hline No. of family & & \\
\hline $1-4$ & 345 & 89.8 \\
\hline $\begin{array}{l}>4 \\
\text { Family income }\end{array}$ & 39 & 10.2 \\
\hline $\begin{array}{l}\text { Family income } \\
10,000-15000\end{array}$ & 44 & 11.5 \\
\hline $16,000-20,000$ & 32 & 13.5 \\
\hline $21,000-25,000$ & 158 & 41.1 \\
\hline$>30000$ & 130 & 33.9 \\
\hline BMI & & \\
\hline Less then 18.5 & 11 & 2.9 \\
\hline $20.5-24.5$ & 173 & 45.1 \\
\hline $24.5-29.5$ & 187 & 48.7 \\
\hline$>30$ & 13 & 3.4 \\
\hline Smoking histor & & \\
\hline Yes & 89 & 23.2 \\
\hline No & 295 & 76.8 \\
\hline Alcohol consun & & \\
\hline Yes & 101 & 26.3 \\
\hline No & 283 & 73.7 \\
\hline
\end{tabular}


Table 2. Association between socio-demography with treatment compliance

\begin{tabular}{lllll}
\hline Variable & \multicolumn{2}{c}{ Compliance level, n (\%) } & p value \\
& High & moderated & low & \\
\hline Age & $7(41.2)$ & $6(35.3)$ & $4(23.5)$ & \\
$40-39$ & $19(22.4)$ & $47(55.3)$ & $19(22.4)$ & .017 \\
$50-59$ & $26(24.3)$ & $56(52.3)$ & $25(23.4)$ & \\
$<60$ & $20(11.6)$ & $114(66.3)$ & $38(22.1)$ & \\
Duration of medication & & & & \\
Less than 3 yrs & $42(26.1)$ & $81(50.3)$ & $38(23.6)$ & \\
3-6 yrs & $21(16.0)$ & $86(65.6)$ & $24(18.3)$ & 0.02 \\
6-10yrs & $2(5.7)$ & $22(62.9)$ & $11(31.4)$ & \\
$<10$ & $7(13.0)$ & $34(63.0)$ & $13(24.1)$ & \\
Drugs per day & & & & \\
1 tab/day & $71(19.1)$ & $221(59.4)$ & $80(21.5)$ & .016 \\
2 tab/day & $1(11.1)$ & $2(22.2)$ & $6(66.7)$ & \\
Meals per day & & & & \\
2 time/day & $1(10.0)$ & $3(30.0)$ & $6(60.0)$ & \\
3 time/day & $49(17.4)$ & $172(61.2)$ & $60(21.4)$ & .05 \\
More than 3 time/day & $22(24.4)$ & $48(53.3)$ & $20(22.2)$ & \\
Drugs near to house & & & & \\
5 minute ofwalking & $7(14.0)$ & $27(54.0)$ & $16(32.0)$ & \\
< than 5min of walking & $64(20.7)$ & $186(60.2)$ & $59(19.1)$ & .006 \\
Travel by bus & $1(4.5)$ & $10(45.5)$ & $11(50.0)$ & \\
\hline
\end{tabular}

Table 3. Multinomial logistic regression analysis of factors associated with treatment compliance in hypertension patients

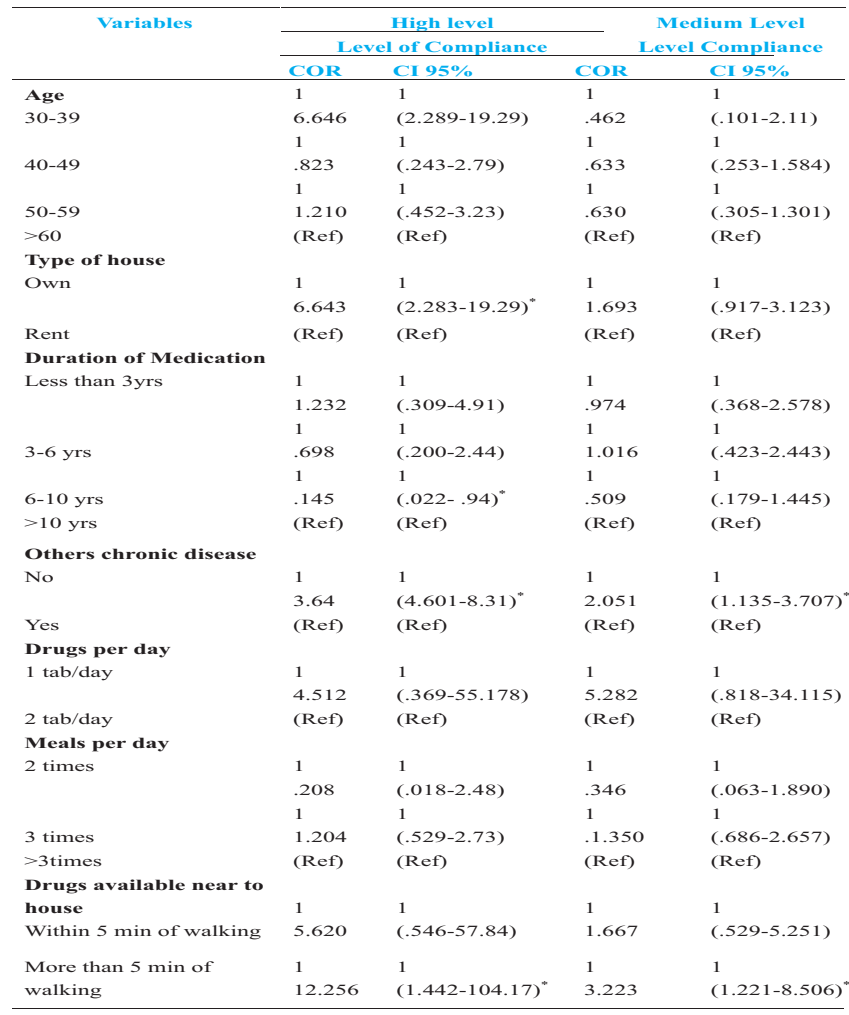

*p value $<0.05$
Table 4. Relationship between adherence scales and treatment compliance

\begin{tabular}{lll}
\hline Level of Adherence & Frequency & Percentage \\
\hline Low Adherence $<6$ & 86 & 22.3 \\
Medium Adherence $6-<8$ & 223 & 58 \\
High Adherence 8 & 75 & 19.7 \\
Total & 385 & 100 \\
\hline
\end{tabular}

Mean score $=6.4219$

\section{DISCUSSION}

Treatment compliance is a very important key factor for hypertensive patients to control the high blood pressure. Out of the 384 patients in the present study showed that high percentage of medium compliance (58\%) among hypertensive patients. This result presents, hypertensive patients needs more awareness to improve the treatment compliance. The finding of the study consistent $60.6 \%$ from the study in Mumbai, India. ${ }^{3}$ In a similar study done in, NorthWest Ethiopia, Southern India and Bangladesh. It was $41 \%$, $75.1 \%$ and $82 \%$ respectively. ${ }^{5-8}$ This may be due to a difference in geography and socio-demographic profile of the study area.

According to the study of rural Bangladesh they found significant relationship between age, sex and socioeconomic status. However, in this study there was significant association of age group (40-49) with treatment compliance but other variable was not significant.

Females were found to be more compliant to treatment than male patients. This study is consistent with other studies Southern India, Bangladesh, Malaysia. ${ }^{7-9}$ Decrease in the proportion of compliance with hypertensive medication among smokers and those who consumed alcohol was consistent with the findings of the study conducted in Mumbai $^{3}$. The number of drugs that patients were taking had a significant association with treatment compliance; this finding revealed that patients having a single drug per day related with good treatment compliance compared to whom taking multiple drugs per day. This finding correlated with another study done in North-West Ethiopia and Korea. ${ }^{5,14}$ The study revealed that patients live in their own house, duration of taking medication (6 to 10 years), drugs available near to house more than 5 minutes of walking and other chronic diseases have statically significant association with medium compliance of medication $(\mathrm{p}<0.05)$ in multilogistic regression. It appears that hypertensive patients had level of compliance; it was high percentage $(58 \%)$ of medium level adherence than other low and high level of adherence $22.3 \%$, and $19.7 \%$ respectively. 
This study shows that low and high level of adherences was not influence by the marital status, number of family member, family income and residential area. This study presents the availability of drugs near to house and decrease chronic disease that causes reduce the prevalence of low compliance.

\section{CONCLUSION}

A high proportion of hypertensive patients have medium level of treatment compliance which was affecting to control high blood pressure. Age group (40 - 49), live in own house, taking a single drug per day, duration of medication, taking 3 times meals per day, drugs available near to house more than 5 minutes of walking and other chronic diseases were factors and significantly associated with treatment compliance. Rest of the variable was not significant and associated with treatment compliance.

That means for many hypertensive patients needs to be improved in treatment compliance. Developing awareness programs to address some of the factors identified is necessary to improve treatment compliance and in turn, to improve high blood pressure control and prevent diseases complication.

\section{ACKNOWLEDGEMENTS}

Researchers deeply express their heartfelt thanks to all patients who participated in the study for immense support and cooperation. Researchers express their deep and sincere gratitude to all those experts for their valuable judgment, constructive feedbacks and enlightening suggestions throughout the study.

\section{REFERENCES}

1. World Health Organization. Global status report on non communicable diseases 2014. World Health Organization; 2014.

2. American Heart Association. About high blood pressure. Dallas, Tex: American Heart Association; 2002.

3. Shah AJ, Singh V, Patil SP, Gadkari MR, Ramchandani V, Doshi KJ. Factors affecting compliance to antihypertensive treatment among adults in a tertiary care hospital in Mumbai. Indian journal of community medicine: official publication of Indian Association of Preventive \& Social Medicine. 2018 Jan;43 (1):53.

4. World Health Organization. Adherence to long-term therapies: evidence for action. World Health Organization; 2003.

5. Teshome DF, Bekele KB, Habitu YA, Gelagay AA. Medication adherence and its associated factors among hypertensive patients attending the Debre Tabor General Hospital, NorthWest Ethiopia. Integrated Blood Pressure Control. 2017;10:1.
6. Kumar V, Kumari B, Rahat E, Fareed S. Frequency of Medication Non-compliance in Hypertensive Patients Presenting with Stroke: A Case-control Study. Cureus. 2019 May;11(5)

7. Rao CR, Kamath VG, Shetty A, Kamath A. Treatment compliance among patients with hypertension and type 2 diabetes mellitus in a coastal population of Southern India. International Journal of Preventive Medicine. 2014 Aug;5 (8):992.

8. Hossain A, Mithila O. Sleep duration and treatment compliance: a population-based cross-sectional study of hypertensive patients in Bangladesh. BMC Research Notes. 2016 Dec;9(1) $: 271$

9. Ramli A, Ahmad NS, Paraidathathu T. Medication adherence among hypertensive patients of primary health clinics in Malaysia. Patient Preference and Adherence. 2012;6:613.

10. Shrestha B, Ferdoush Z, Rabbi F, Hossain A. Adherence to medications among Nepali hypertensive population: a hospitalbased cross-sectional study. Biomedical Journal. 2018;2:5.

11. Osamor PE, Owumi BE. Factors associated with treatment compliance in hypertension in South-West Nigeria. Journal of Health, Population, and Nutrition. 2011 Dec;29(6):619.

12. Pan J, Wu L, Wang H, Lei T, Hu B, Xue X, Li Q. Determinants of hypertension treatment adherence among a Chinese population using the therapeutic adherence scale for hypertensive patients. Medicine. 2019 Jul;98(27).

13. Morisky DE, Ang A, Krousel-Wood M, Ward HJ. Predictive validity of a medication adherence measure in an outpatient setting. The Journal of Clinical Hypertension. 2008 May;10(5) :348-54.

14. Choi HY, Im Jung Oh JA, Lim J, Kim YS, Jeon TH, Cheong YS, Kim DH, Kim MC, Lee SY. Factors affecting adherence to antihypertensive medication. Korean Journal of Family Medicine. 2018 Nov;39(6):325 